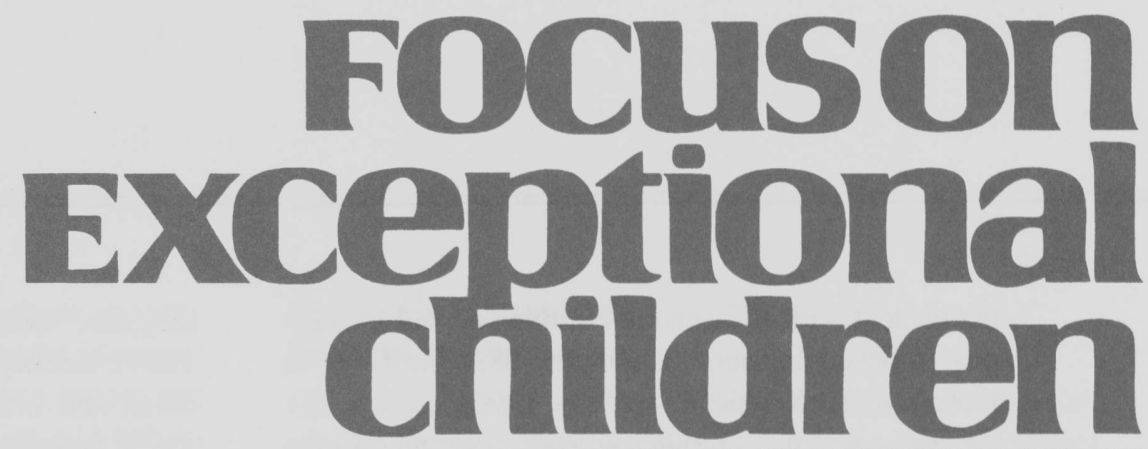

\title{
Group Counseling for People With Physical Disabilities
}

\author{
Hanoch Livneh, Lisa M. Wilson, and Robert E. Pullo
}

The origins of group work as applied to individuals with physical disabilities can be traced to the pioneering work of Joseph Pratt, a physician at the Massachusetts General Hospital, who, as early as 1905 , used group methods to assist patients with tuberculosis (Gust, 1970; Miller, Wolfe, \& Spiegel, 1975). Upon noticing the role group members played in positively affecting one another's emotional adjustment to their illnesses, Pratt later expanded his work to include patients with other chronic illnesses (Durkin, 1972). Pratt's approach valued two components embedded in group methods-support and inspiration - as being of particular importance in light of the feelings of depression and isolation often associated with long-term disabling conditions.

\section{MERITS OF GROUP COUNSELING}

Group counseling with individuals who have physical disabilities has much to offer. Among its advantages for this population are the following:

1. Groups can help people who strive toward the resolution of some common problem (e.g., accepting functional limitations, dealing with employer's prejudice) by providing them with the opportunity to learn from one another through sharing common concerns and problems and generating solutions to obstacles and difficulties (Gust, 1970).

2. Groups offer members a forum for the emotional release of burdensome personal issues in a supportive setting. Realizing that others face similar problems tends to lessen the anxiety and fear that accompany various disabling conditions.

3. The group experience can partially alleviate the stress, pain, and misery often generated by physical disability and further aggravated by social isolation, separation from family and friends, and perceived alienation from one's own body (Chubon, 1982; Jacobs, Harvill, \& Masson, 1988).

4. The group experience eases the transition into the able-bodied community. Through modeling and various socialization and social skill building exercises (e.g., in assertiveness and frustration tolerance), group members learn and practice how to

Hanoch Livneh is Coordinator of the Rehabilitation Counseling Specialization at Portland State University in Portland, Oregon. Lisa M. Wilson is Associate Coordinator of the Rehabilitation Counseling Specialization at Portland State University, as well as the coordinator of Disability Services for Students at the university. Robert E. Pullo is a professor in the Rehabilitation Services Program of the Department of Health and Rehabilitation at the University of Maine at Farmington. This article was adapted from Introduction to Group Counseling published by Love Publishing Company. 
better deal with the outside community and its various imposed barriers (Chubon, 1982; Gust, 1970; Patterson, McKenzie, \& Jenkins, 1995).

5. Through the group modality, leaders are able to develop a more accurate and comprehensive psychosocial assessment of group members (Salhoot, 1977).

6. Development of a social support network is often facilitated through the relationships formed during group counseling. Issues such as empowerment, hopefulness, search for meaning, and gaining spirituality require a support network to be fully explored (Olkin, 1999). A successful platform for their exploration can be provided within a group context.

\section{NEEDS AND CONCERNS OF PEOPLE WITH DISABILITIES}

Group counseling strategies for people with disabilities have been applied to a wide range of physical and psychiatric disorders. For example, groups have been conducted for people with psychosomatic conditions, such as ulcers, asthma,

\section{FOCusOn Exceptional children}

ISSN 0015-511X FOCUS ON EXCEPTIONAL CHILDREN (USPS 203-360) is published monthly except June, July, and August as a service to teachers, special educators, curriculum specialists, administrators, and those concerned with the special education of exceptional children. This publication is annotated and indexed by the ERIC Clearinghouse on Handicapped and Gifted Children for publication in the monthly Current Index to Journals in Education (CIJE) and the quarterly index, Exceptional Children Education Resources (ECER). The full text of Focus on Exceptional Children is also available in the electronic versions of the Education Index. It is also available in microfilm from Xerox University Microfilms, Ann Arbor, MI. Subscription rates: individual, \$36 per year; institutions, \$48 per year. Copyright (C) 2004, Love Publishing Company. All rights reserved. Reproduction in whole or part without written permission is prohibited. Printed in the United States of America. Periodical postage is paid at Denver, Colorado. POSTMASTER: Send address changes to:

Love Publishing Company

Executive and Editorial Office P.O. Box 22353

Denver, Colorado 80222

Telephone (303) 221-7333

\section{EDITORIAL BOARD}

Edwin Ellis

University of Alabama
Tim Lewis

University of Missouri

Chriss-Walther Thomas

University of Kansas

Susan T. Warhover Editor
Stanley F. Love

Publisher migraine headaches, and neurodermatitis (Scheidlinger, 1984), sensory disabilities (Seligman, 1982), and neuromuscular and orthopedic impairments (Lasky \& Dell Orto, 1979; Seligman, 1982). These groups can be established in inpatient settings (hospitals and rehabilitation centers) as well as outpatient (community) settings. Hospital-based groups typically focus on the participants' immediate medical concerns and initial reactions to the onset of disability (e.g., dealing with medical staff and procedures and feelings of anxiety and being overwhelmed by daily stress), whereas community-based groups confront such concerns as adverse public attitudes, long-term functional limitations, and prospects of employment.

More specifically, the needs and concerns that people with disabilities customarily manifest can be classified into eight major categories:

1. Physical needs (e.g., mobility, activities of daily living, pain control)

2. Psychological needs (e.g., alleviation of anxiety and depression, anger control, frustration tolerance)

3. Social needs (e.g., appropriate interpersonal communication, assertive behavior, managing stigma)

4. Vocational needs (e.g., employment training, job interviewing, job maintenance)

5. Financial needs (e.g., disability benefits, gainful employment)

6. Environmental barriers (e.g., accessibility, transportation, shopping)

7. Attitudinal barriers (e.g., inappropriate language, social prejudice, disability-related stigma)

8. Recreational needs (e.g., leisure-time activities)

This wide array of needs and concerns of clients with disabilities has necessitated various therapeutic group formats. Four general group modalities seem to dominate the field:

1. Educational groups. These didactic groups impart factual information to participants. For example, the leader discusses and clarifies specific treatment procedures, necessary lifestyle changes, and appropriate vocational pursuits. This type of group is aimed at helping members make appropriate decisions concerning these life issues.

2. Social support groups. Support groups, typically generated from self-help and peer-helper group models, provide participants with the opportunity to support one another and create a forum for exchanging ideas, concerns, and problem-solving methods.

3. Psychotherapeutic groups. The emphasis in psychotherapeutic groups is on the affective domain and increased self-understanding. By providing participants with cathartic outlets, these groups directly 
address pressing emotional issues such as anxiety, depression, anger, and changes in personal identity.

4. Coping and skill training groups. These groups are more readily aligned with the cognitive and behavioral than with the psychodynamic camps. Participants are trained to cope effectively with their disability and its implications. Specific skills are taught during group sessions and later practiced in the external environment.

\section{THERAPEUTIC FACTORS OF GROUPS FOR PEOPLE WITH DISABILITIES}

Yalom's (1985) curative factors inherent in group counseling seem to be directly relevant to groups whose members have physical disabilities (Buchanan, 1975; Jacobs et al., 1988; Mann, Godfrey, \& Dowd, 1973; Seligman, 1982; Weiner, 1988). These principles are reviewed only briefly here in relation to physical disabilities.

\section{Instillation of Hope}

The expectation of recovery or of overcoming disability and the threat of future bodily deterioration, coupled with observation of the gradual progress of other group members, is a powerful motivating force. Participants perceive this progress and vicariously identify with group members who overcome adversity.

\section{Universality}

The perception of uniqueness is dispelled in groups. Members quickly discover that their problems, concerns, and fears are shared by others and that they do not suffer alone. The feeling of commonality tends to decrease social isolation and withdrawal.

\section{Imparting Information}

Didactic instruction (e.g., informing participants of new medical procedures, discussing anticipated psychological reactions associated with the particular impairment), as well as advice and suggestions by the group leaders, rehabilitation personnel, or other group members on the availability of health-related services, job opportunities, and so on, can reduce client ignorance and anxiety about the unknown future.

\section{Altruism}

Participants learn how to be helpful and useful to others. Group members derive many personal benefits from sharing experiences, suggestions, insights, and reassurances with other members. Veterans and novices alike benefit from the mutual sharing of these experiences.

\section{Corrective Recapitulation of the Primary Family Group}

Groups for people with or without disabilities bear certain resemblances to families, both in structure and dynamics. Group leaders and members are capable of eliciting feelings and behaviors that once were directed at parents and siblings. When early family dynamics and conflicts (e.g., dependence-independence, scapegoating) are relived in the group, corrective feedback can be applied to faulty perceptions and maladaptive behaviors.

\section{Development of Socializing Techniques}

In many instances, preparing individuals with disabilities to go into the community is predicated on their acquiring social skills. Group members role-play various social situations with the goal of acquiring useful and constructive interpersonal behaviors.

\section{Imitative Behavior}

Emulating the behaviors of successful role models has been a cornerstone of the rehabilitation movement. Participants learn how to model their thoughts and behaviors after those of group leaders and other members who have successfully coped with their physical and social environments (e.g., gained independence, secured a job).

\section{Group Cohesiveness}

Belonging to a cohesive group produces an attitude of solidarity in the members. During group interactions, members share feelings of acceptance and mutual respect, which results in a more positive self-concept.

Groups also afford their members the opportunity to ventilate strong emotions (e.g., anger, fear, loss, anxiety, joy). In the supportive social environment of the group, relieving these pent-up emotions constitutes an important curative factor. It may pave the way to gaining insight into one's problems as participants recognize their present emotional reactions and the connection to those experienced earlier with members of the nuclear family.

\section{GOALS OF GROUP COUNSELING}

A review of the literature on the purposes and goals of group counseling for people with disabilities, and consideration of the problems and needs of this population, revealed that three primary group counseling goal categories seem to predominate: affective, cognitive, and behavioral goals.

\section{Affective Goals}

Goals considered under this category pertain to group approaches that address the client's emotional well-being 
(Democker \& Zimpfer, 1981; Forester, Kornfeld, Fleiss, \& Thompson, 1993; Henkle, 1975; Howard, 1983; Konstam, 1995; Kriegsman \& Celotta, 1981; Rose, 1989; Salhoot, 1977). These goals include:

1. Provide the opportunity for emotional catharsis. Group counseling offers group members the opportunity to express and share common feelings, experiences, and problems (e.g., depression, despair, helplessness, frustration, anger) in a safe environment.

2. Give members emotional support. Receiving support from peers and group leaders is a cardinal step in the process of adapting to disability.

3. Reduce anxiety. Overcoming initial fear and anxiety paves the way to successful rehabilitation.

4. Provide members with the opportunity to recognize that they are not alone. Helping group members to realize that others have similar experiences and emotional reactions is important.

\section{Cognitive Goals}

Cognitive goals are those directed at thought-related or perceptive processes. They are also geared toward the individual's knowledge and understanding of his or her disability and its implications for future functioning. More specifically, these goals are to (Democker \& Zimpfer, 1981; Kriegsman \& Celotta, 1981; Lyons, Sullivan, \& Ritvo, 1995; Singler, 1982):

1. Assist the group member to increase self-acceptance and self-esteem. The concept of self (self-confidence and personal worth) is intimately linked to the acceptance of self with a disability and the subsequent personal adjustment.

2. Help the person confront reality. Clients receive opportunities to test reality and form more realistic evaluations of their assets and limitations.

3. Provide the member with accurate and comprehensive information. Information might include prognosis of condition, use of medication, available sexual outlets, and other facts to foster a sense of personal control and to demystify the nature of the disability.

4. Improve personal outlook. Through the use of imagery, meditation, and relaxation training, members can achieve a more positive outlook.

\section{Behavioral Goals}

The primary purpose of behavioral goals is to decrease clients' maladaptive behaviors (e.g., dependency, social withdrawal) and replace them with adaptive ones (e.g., independence, appropriate interpersonal relationships). Accordingly, behavioral goals might be to (Democker \& Zimpfer,
1981; Kriegsman \& Celotta, 1981; Mann et al., 1973; Miller et al., 1975; Rose, 1989):

1. Assist dependent group members in overcoming dependence (in a mutually supportive environment).

2. Increase the client's ability to cope more effectively with the disability and its associated functional limitations.

3. Provide a setting wherein group members can safely and gradually practice and rehearse new skills and behaviors.

4. Improve interpersonal communications and socialization skills.

5. Assist members in setting and implementing new and more appropriate personal, educational, and vocational goals.

The affective, cognitive, and behavioral goals listed here do not constitute a complete roster of all possible counseling goals for groups designed for people with disabilities. Rather, they represent the more common types of goals often suggested in the literature. Goals vary with the type of disability and the functional limitations the disability imposes, the immediate needs and concerns of each member or the group as a whole, and the leader's philosophy, knowledge, and skills (Democker \& Zimpfer, 1981; Salhoot, 1977).

\section{PHASES OF GROUP COUNSELING FOR PEOPLE WITH DISABILITIES}

Most authors perceive the group process as being composed of two or possibly three essential segments (Kriegsman \& Celotta, 1981; Lasky, Dell Orto, \& Marinelli, 1984; Mann et al., 1973; Oradei \& Waite, 1974; Power \& Rogers, 1979). In a three-phase model, the first phase may be construed as one of relationship building. In groups for people with disabilities, group members are encouraged to talk about their disability, its etiology, major presenting problems, and so on. The discussion typically evolves around issues related to factual information concerning the disability. Any misconceptions pertaining to the disability, its causes, its nature, and anticipated progress are clarified. Using methods such as reflection, clarification, self-disclosure, positive reinforcement, role-playing, and establishing a relaxed atmosphere, group leaders encourage participants to develop mutual trust, openness, involvement, personal awareness and responsibility, and commitment (Kriegsman \& Celotta, 1981).

During these initial sessions, group leaders play an active role by initiating topics for discussion, offering support and encouragement, raising questions, and, in general, 
facilitating an active exchange of experiences and ideas. In more structured groups (see, e.g., Lasky et al., 1984; Roessler, Milligan, \& Ohlson, 1976), individual goal identification, clarification, and planning are paramount.

The second phase in groups for people with disabilities is normally geared toward (a) encouraging members to express and explore their feelings regarding the disability, (b) helping participants become aware that others share similar emotions, and (c) helping members develop, based on this gained awareness, a mutual understanding and closeness (Oradei \& Waite, 1974; Power \& Rogers, 1979). During this middle phase, group leaders shift their role from that of active structure providers and discussion guiders to less overt leadership, allowing participants to ventilate anxieties and fears about their future, to express anger and frustration over interpersonal conflicts, and to initiate most discussion topics.

The leaders clearly direct attention to helping the participants, through ego-supportive feedback, to gain insight into their adjustment difficulties, while also providing the opportunity for members to learn from one another's experiences and achieve a more positive outlook on life with a disability (Power \& Rogers, 1979). Group leaders, therefore, pay particular attention to exploration of self, interpersonal dynamics, and the functioning of the group as a cohesive unit (Lasky et al., 1984; Mann et al., 1973).

The third phase of group counseling for people with disabilities centers on the development of coping and problem-solving methods, with special emphasis on resocialization, future planning, and community reintegration. During this phase, members are assisted in assessing, selecting, and prioritizing their future needs and objectives and are taught ways to implement those objectives. Those who have recently re-entered the community following the onset of their disability are given emotional support and feedback on their progress. They also receive ample opportunity in the group to practice their newly learned behaviors. Group leaders and veteran participants often model community-based, adaptive behavior to clients who have recently sustained a disability. Lasky et al. (1984) viewed this final phase as directed toward "life and living," with an emphasis on creating resources that will help members apply their newly acquired skills in daily, community-based activities.

\section{STRATEGIES FOR GROUP SESSIONS}

In the following discussion, counseling strategies are described for three types of physical disability groups: (a) sensory disabilities groups (visual and auditory), (b) orthopedic and neuromuscular disabilities groups (spinal cord injury and cerebrovascular accident, or stroke), and (c) other physical disabilities groups. Cross-disability group strategies developed specifically for rehabilitation settings are also discussed, including (a) structured, coping-based interventions, (b) self-help group methods, and (c) vocationalrelated (placement-oriented) procedures.

\section{Approaches With Sensory Disabilities Groups}

The intent of this section is, first, to provide information about the physical and psychosocial functional limitations inherent in some of the commonly encountered sensory disabilities and, second, to present specific group strategies and issues directly related to counseling these populations.

\section{Visual Impairment Groups}

The chief difficulties people with visual disabilities encounter include the following (Keegan, 1974; Lindemann, 1981; Van Boemel \& Rozee, 1992; Vander Kolk, 1983):

- Hindered mobility (restriction of freedom of movement that compromises the ability for independent living)

- Dependence on the social environment

- Diminished socialization skills

- Anxiety resulting in avoidance of other people and increased isolation

- Accepting the reality of the disability and altered body image

- Coping with frustration and anger and the related lack of assertiveness

In an early attempt to use group strategies with people with visual impairments, Cholden (1953) sought to offer group members the opportunity to verbalize and gain insight into their feelings. He argued that blind people have difficulty expressing certain feelings because of their inability to perceive visual and social cues that customarily encourage or hinder the expression of emotions during interpersonal transactions. During group sessions, members were encouraged to express and gain understanding of their personal reactions to their disability. This activity was followed by discussion of the means available for managing and controlling emotions. Cholden concluded that these group experiences fostered and enriched emotional communications in people who are blind.

Herman (1966) discussed the use of group therapy for blind people in rehabilitation settings. In his weekly groups, discussion topics included (a) denial of blindness and its implications, (b) depression and despair following realization of the visual loss and their prevention of successful adaptation, (c) dependency and low self-esteem and how they work against the struggle for independence, (d) devaluation of self and guilt feelings, and (e) avoidance of social situations. Based on his clinical impressions, Herman 
concluded that the group experience was instrumental in developing closeness among the members.

Wilson (1972) and Goldman (1970) further contributed to the field's understanding of the psychological reactions of persons with visual impairments and suggested specific strategies for helping visually impaired people cope with their psychological and behavioral difficulties. Wilson (1972) discussed two types of group therapy for people with visual impairments. The first, exploratory group therapy, delves into interpersonal issues that seem to have caused the psychological and behavioral problems. The second, supportive group therapy, is geared toward providing reassurance, encouragement, education, and advice on how to manage daily problems.

Using what he termed "encounter microlabs" with a group of young people with visual disabilities, Goldman (1970) sought to encourage participants to become aware of their own and others' feelings and their own and others' bodies. Goldman viewed encounter therapy as a multifaceted concept encompassing elements of various therapeutic modalities (e.g., Gestalt, person-centered, psychodynamic) in which action, holism, awareness, and self-growth are underscored. In a comprehensive discussion, he delineated five classes of techniques used in encounter microlabs:

1. Techniques to reduce initial anxiety-exercises involving deep breathing, progressive relaxation, and corpse posture (lying down and "letting your body go").

2. Techniques to initiate interactions - milling exercises (moving randomly around the room, first nonverbally and then verbally, and using touch) and go-around exercises (going around to every person, touching him or her, and making an "I feel" statement).

3. Techniques for building trust-falling and catching (falling backward into the arms of others), lifting (being lifted up from the floor by others), and blind walk (being paired with another member designated a "sighted guide" and together exploring the environment).

4. Techniques for eliciting and working through problems - a brief lecture, followed by an exercise. The lecture, covering topics such as honesty, openness, directness, and emphasizing the present, is followed by exercises including secret pool (each group member anonymously writes down a secret about a problem he or she is experiencing, each secret is read aloud by another member, and the group discusses its meaning and provides feedback) and magic shop (members are offered the opportunity to purchase anything they desire from a magic shop owned by the group leader).
5. Guided fantasy techniques - exercises to assist group members in conflict resolution and goal setting, strategies to improve perception of body and physical appearance (e.g., stretching out and relaxing, exploring internal and external body boundaries), fantasizing significant others talking about oneself, and future projection (imagining what one will be doing in the distant future).

From his studies, Goldman (1970) concluded that these exercises increase self-assertiveness and feelings of independence as well as self-awareness and empathy toward others.

Groups are an important setting for addressing other concerns, as well. For example, a concern often raised in groups with people who are blind centers on sexual matters (e.g., dating, marriage, sex, pregnancy). Employing group therapy with adolescent girls with multiple disabilities, Avery (1968) offered participants the opportunity to learn about sexuality issues. Through reflection of feelings, thought clarification, interpretation of emotions and behaviors, and providing answers to questions on sexual issues, Avery allowed the girls to ventilate emotional concerns in a supportive atmosphere and provided related factual information.

Another concern revolves around interactions with sighted people (Cholden, 1953; Welsh, 1982). During these interactions, feelings of hostility and resentment by the person with visual impairment are often evident. Counseling strategies geared toward appropriate assertiveness skills and toward developing a more positive self-concept are beneficial when these concerns arise (Welsh, 1982).

Many group members also benefit from discussions about how to cope with the functional limitations the visual impairment imposes. Group members might discuss the impact of these limitations on their ability to independently perform various tasks and activities in the community and how this might affect their self-concept (Inana, 1978; Welsh, 1982). Group leaders seek to facilitate acceptance of the condition, internalization of the concept of personal loss, and the development of a more realistic self-perception.

Finally, groups must attend to personal skill building. The skills that are taught may be applied in vocational training programs, in securing appropriate employment, and in life in general. Roessler (1978) reported on a personal achievement skill training program for visually impaired people. Participants were taught problem-solving, decisionmaking, and self-modification skills. They engaged in exercises and activities that enabled them to improve their communication skills, to identify and prioritize goals, and to implement and monitor the progress of those goals. This group achieved higher levels of goal attainment and selfesteem than the control group did. 
Group counselors working with clients who have visual impairments should pay particular attention to:

1. Periods of silence. Periods of silence are threatening to people who are blind (Welsh, 1982). Silence generates discomfort, anxiety, and resentment and may even lead to paranoid projection by some participants. Leaders must therefore remember to use verbal and directive techniques (e.g., audible reinforcers, inviting participants to speak) rather than nonverbal methods (e.g., eye contact, head nodding). Co-leadership is also recommended as a means to bridge periods of silence (Keegan, 1974; Welsh, 1982).

2. Group structure. When counseling people who are blind, the need for more structure of group sessions is inherent (Welsh, 1982). This is particularly important for members who are congenitally blind.

3. Trust-building techniques. Building trust is important, since many blind people often mistrust and resent sighted people as well as others who are blind. Activities Goldman (1970) discussed, described earlier (e.g., "falling and catching," "blind walk"), are recommended (Keegan, 1974; Welsh, 1982).

4. Selection of group members. In choosing group participants, degree of visual impairment, its cause, and age of onset should be considered. Also, clients' levels of denial, optimism, resentment, and anxiety are important variables in establishing a well-balanced group (Routh, 1957; Welsh, 1982).

\section{Hearing Impairment Groups}

The most pervasive difficulties that beset people who have hearing impairments are as follows (Lindemann, 1981; Ostby \& Thomas, 1984):

- Impaired communication

- Negotiating various environmental features that may directly impact their personal safety (e.g., inability to respond to a ringing phone or to react to honking horns or police sirens)

- Experiential deprivation and isolation from significant others

- Maladaptive behavioral patterns (e.g., withdrawal, rigidity, suspiciousness, immaturity, denial) that prevent effective social interaction with hearing peers

- Handling frustrations related to inadequate communication and isolation

- Coping with overprotective and dependency-fostering parents and others

In an early effort to apply group counseling strategies to hospital patients who were deaf, Robinson (1965), a hearing psychiatrist, employed manual communication methods in working with a group of six participants. The group proved successful in offering participants the opportunity to ventilate feelings toward other group members and the therapist. Portner (1981) described a YWCA group for women who were deaf that focused on problems of living, group members' denial of impairment, projection of frustrations and anger toward hearing people, feelings of inferiority, and difficulties in communicating with mates.

As previously mentioned, a common problem of people who are deaf is their experiential deprivation and its subsequent progression into a lack of social assertiveness. In an effort to rectify problems with assertiveness in clients with hearing impairment, Sedge (1982) sought to teach the clients to openly express their feelings and assert themselves in situations where communication barriers exist. Because prior research had demonstrated the effectiveness, for hearing-impaired people, of assertiveness training in increasing assertive behavior, improving self-concept, elevating selfconfidence, improving speech fluency, and increasing interactional activities, Sedge (1982) developed an assertiveness training model for hearing-impaired servicemen that employed mini-lectures, modeling, role-playing, overt and covert behavior rehearsals, relaxation training, and homework assignments. Training goals were to discriminate between passive, assertive, and aggressive behaviors; identify and accept personal rights and those of others; exert control in situations where communication is impaired; and communicate more effectively within the environment. The training group demonstrated significant increases in level of assertiveness and in self-concept when compared to a control group.

Sarti (1993) described a mental health program for young adolescents with hearing impairments and marked ego deficits that was conducted at the Rhode Island School for the Deaf. Using what the program developers called "Prep House" group therapy, the program provided participants with both the necessary therapeutic group conditions (e.g., allowing students to express their needs and conflicts in a safe atmosphere, practice in personal and social coping skills) and communicative accommodations (e.g., role-playing, "rapping," videotaping of group sessions) to enhance their egos. Reports by group therapists, teachers, parents, and participants lent support to this therapy's success in improving participants' self-concept, impulse control, and reality testing.

Anderson, Melin, Scott, and Lindberg (1995) demonstrated the effectiveness of a behavioral group approach employing relaxation, self-modeling, exposure, coping, and skill training in helping elderly people cope better with their hearing impairment. The treatment effectiveness was further demonstrated during a 1-month follow-up assessment of participants. 
Concerns commonly raised and discussed in groups for people who are deaf include (Card \& Schmider, 1995; Schein, 1982) feelings of isolation because of a communication handicap (e.g., difficulties associated with accurately perceiving the motives of others); appropriate expression of feelings such as anger and frustration; interpretation of symbolic behaviors, often manifested in nonverbal (e.g., facial) cues and messages (of particular importance in the prelingually deaf population); and appropriate rules and customs regarding dating and sex-oriented issues (most prevalent in individuals with prelingual deafness and those educated in restrictive residential settings).

Schein (1982) asserted that to successfully manage group-raised concerns related to isolation, lack of effective communication, and similar issues, the leader should realize the importance of emotional ventilation. In a group context, emotional ventilation allows members to realize that their problems and frustrations are not unique. Furthermore, mutual expression of feelings and exchange of concerns increase self-esteem, alleviate anxiety, and reduce interpersonal awkwardness.

Card and Schmider (1995) argued that in considering group composition, group leaders should pay particular attention to participants' age of onset and severity of hearing loss, cognitive processing ability, language skills, psychosocial adjustment, and family communication patterns.

Group counselors working with deaf and hearingimpaired populations should consider the following:

1. Arrangement of the physical setting. In organizing the group setting, the leader should pay particular attention to the participants' seating arrangements (members must be able to see all other members and the leader at the same time). Since barrier-free sightlines must be ensured, semicircular or rectangular seating patterns are often recommended (Card \& Schmider, 1995; Schein, 1982). Lighting must facilitate nonverbal and manual communication, and appropriate acoustics must be ensured for members who use hearing aids (Speer \& O'Sullivan, 1994).

2. Use of sign language. The choice of communication mode in group counseling in which most or all of the participants have hearing impairments is of utmost importance. The traditionally preferred mode has been American Sign Language (ASL; SilbermanMiller \& Moores, 1990). The leader, whether hearing impaired or nonimpaired, must possess comprehensive ASL skills to function as an effective counselor (Silberman-Miller \& Moores, 1990).

3. Use of an interpreter. Although employing a sign language interpreter is often suggested to facilitate communication in these groups, it is not without difficulties (Schein, 1982). The addition of a "third party" may adversely affect group dynamics by hindering the establishment of relationships and impeding the expression of many feelings and thoughts (Portner, 1981; Silberman-Miller \& Moores, 1990). Also, because the interpreter cannot attend to more than one person's verbalization at a time, he or she is placed under pressure to keep pace with the messages, and the group leader has to assume the role of "verbal traffic director" (Schein, 1982).

When an interpreter is used, he or she should be easily visible to everyone and preferably seated next to the group leader. Ideally, even when an interpreter is used, the leader should be adept at signing for both practical reasons (speed in communication) and psychological reasons (learning sign language is considered to be a gesture of respect for the person who is hearing impaired) (Card \& Schmider, 1995; Riekehof, 1987).

4. Eye strain. The leader must be alert to the strain placed on members' vision as a result of their total reliance on the manual communication modality (Schein, 1982).

5. Deaf-hearing group mixture. The ratio of group members with hearing impairment to those whose hearing is normal (e.g., people with other disabilities, family members, staff members) partially dictates group communication modalities, structure, and content (Schein, 1982). Group leaders should, accordingly, take into account the participants' oral and manual communication skills, degree of hearing impairment, age of onset of the impairment (prelingual versus postlingual), and social and emotional maturity when planning the content and structure of sessions.

6. Gender and number of group leaders. It is often recommended that groups for people with hearing impairments be co-led by a male and female leader. Co-leaders can maintain better eye contact with all group participants as well as accommodate different modes of communication. If they are of different genders, they can also offer better opportunities for participants to practice gender-role issues (Card \& Schmider, 1995).

\section{Approaches With Orthopedic and Neuromuscular Disabilities Groups}

\section{Spinal Cord Injury Groups}

Individuals who have sustained spinal cord injury (SCI) are primarily faced with the following limitations (Craig, Hancock, Chang, \& Dickson, 1998; Crewe \& Krause, 1987; Donovan, 1981):

- Mobility impairment (i.e., restricted ambulation and often inaccessible environments) 
- Problems with personal hygiene, dressing, eating and drinking, toileting, and writing (specific impairments depend upon the nature and severity of the injury)

- Difficulties (particularly in men) in sexual performance

- Feelings of depression, passivity, embarrassment, helplessness, and pain

- Denial of the injury's degree of severity and its permanency, resulting in unwillingness to cooperate with rehabilitation efforts

- Disruption of familial, social, and vocational activities

Mann et al. (1973), in counseling people with spinal cord injury, established four group goals:

1. To help participants increase their self-concepts and thereby positively impact their total rehabilitation efforts

2. To help dependent members overcome dependency in a mutually supportive environment

3. To provide a setting wherein interpersonal relationship issues could be identified, discussed, and, when necessary, resolved

4. To modify members' perceptual distortions about other people

The groups were structured so that participants who had sustained their injuries earlier than others could assist newer clients in accepting the limitations imposed by their disability and in adjusting to life with it. The leader and other participants provided feedback and reinforcement related to progress. Group discussion also focused on assisting clients to recognize how they can make maximum use of their strengths and remaining physical abilities.

Reporting a short-term group counseling approach for people with spinal cord injury, Miller et al. (1975) described a more structured, didactic-informative group. Their approach was aimed at providing information on the physiology and associated problems (e.g., sexual, muscular) of spinal cord injuries. Group members showed positive changes in self-concept as well as increases in their knowledge and understanding of the impairment.

The concern with sexuality expressed by many people with spinal cord injuries led several clinicians to establish groups that specifically addressed this issue (Banik \& Mendelson, 1978; Melnyk, Montgomery, \& Over, 1979). In these groups, clients were encouraged to talk about their concerns and feelings related to sexual relations. The discussion commonly revolved around fears of rejection by sexual partners when satisfactory functioning was impaired. Using lectures and films, the group leaders disseminated specific and technical information on the psychophysiology of sex to relieve anxiety and avoidance of the issue. In general, the group leaders sought to balance informative coverage of sexual alternatives and means of expression with small-group discussion, role-playing, and behavioral rehearsal of effective partner communication, sexual adaptation, and other related concerns (Melnyk et al., 1979).

Melnyk and his co-workers (1979) developed the following weekly format for their sexual counseling groups: member introduction through "games"; discussion of program goals and member problem areas; small-group work using self-guided imagery for enhancing sensuality and large-group discussion of communication issues; verbal and nonverbal communication followed by discussion of films on sex education and techniques; and discussion of body image followed by discussion of spinal cord injuries and the use of sexual aids.

A comprehensive structured group counseling program for people with SCI was proposed by Roessler et al. (1976). Termed the Personal Achievement Skills (PAS) training program, it strived to (a) develop participants' self-awareness of their personal values and capacities and their acceptance of other group members, and (b) develop skills in areas such as communication, problem identification, goal setting, and action implementation. Typical member goals included independent community living, educational-vocational training culminating in successful job placement, identification of recreational and leisure needs and how to meet them, and family counseling focusing on sexual issues.

Bowers et al. (1987) described a structured, active mastery support group for young males who had sustained spinal cord injury. The 1-hour weekly support group meetings emphasized self-expression, especially regarding feelings about the injury and the resulting dependence upon others; the attainment of emotional independence; examination of client-rehabilitation staff relationships; and assessment of public attitudes toward people with physical disabilities. Structured group topics discussed developing independence (e.g., planning for work and leisure-time activities and travel), role transitions (e.g., changes in social, vocational, and sexual functioning roles), selfexpression (e.g., communication with friends, dealing with anger), and communication with the rehabilitation team.

In a longitudinal study, Craig et al. (1998) sought to assess perceptions of control among people who had sustained SCI. The researchers offered a 10 -week, 11/2-hour per week cognitive-behavioral therapy group program that focused on perceptions of control, self-esteem, assertion, sexuality, and family relations to SCI patients during hospital rehabilitation. Following group participation, patients reported increased internal locus of control when compared to a control group that received traditional rehabilitation 
services only. This study suggests that providing structured group cognitive-behavioral therapy during rehabilitation is a useful therapeutic modality for people with SCI.

Counselors who conduct group sessions with clients with SCI should pay attention to the following considerations:

1. Appropriateness of the physical setting. The setting for group sessions must be totally free of architectural barriers. The leader may have to make or arrange for physical modifications prior to the first session (Seligman, 1982).

2. Attention to client fatigue. Because fatigue plays a major role in the lives of individuals with SCI, each session should be limited to a maximum of 2 hours (Roessler et al., 1976).

3. Knowledge of spinal cord injuries. The group leader(s) should thoroughly understand spinal cord injuries and their functional implications (Roessler et al., 1976) and should be able to recognize and deal with emergency medical situations that might arise.

4. Personal comfort with sexual issues. Because a large portion of group work with this population focuses on alternative sexual outlets, sexual aids, and the like, group leaders should become familiar with these topics and be comfortable discussing these issues in a group format.

5. Tailoring of the group therapy modality to participants' psychosocial level of adaptation. Participants at different phases of adaptation will likely benefit most from different group formats. Therefore, group leaders may consider offering two, or more, group formats. For example, participants who are comfortable sharing experiences with others may benefit more from a discussion-oriented group format, whereas those who are coping with earlier phases of adaptation may find structured didactic group formats more suitable for their immediate needs and concerns (Fow \& Rockey, 1995).

\section{Cerebrovascular Accident Groups}

The major physical and psychosocial difficulties associated with cerebrovascular accidents (CVAs), or strokes, are as follows (Anderson, 1981; Singler, 1982):

- Perceptual-spatial deficits (including problems with visual-motor coordination, visual dysfunctions, spasticity, and seizures)

- Impairment of cognitive functioning (speech and language abilities, learning, abstract reasoning, memory, attention, and concentration)

- Deficient affective performance (emotional reactions including anxiety, denial, depression, frustration, agitation, anger, and shame)
- Behavioral involvement (increased impulsivity, restlessness, social discrimination)

- Communication problems that result from deterioration in cognitive functioning (such as verbal fluency and involvement of the affective domain), causing lower frustration threshold and other emotional lability manifestations

Because the psychophysiological implications of CVA are many, the counseling goals delineated by clinicians address a wide array of concerns, issues, and problems. The two major goals D'Afflitti and Weitz (1974) identified for their patient-family, hospital-based group sessions were encouraging patients and families to (a) share feelings about the stroke to facilitate a better adjustment to the impairment and (b) use appropriate community resources and supports available to them. As expected, patients and their family members raised numerous issues during the sessions. Among them were loss of control of certain body parts and functions and its effect on self-esteem, attempts at denial of impairment, expression of resentment and anger by family upon realizing the magnitude of the impairment and ensuing guilt feelings, and attempts at restitution and resolution of problems by discussing life prior to the disability, accepting the loss, and adjusting to life with a disability.

D'Afflitti and Weitz (1974) reported that discussion of these issues in a group format seemed to be positively associated with facilitating communication between patient and family and creating more realistic expectations about the future, such as return to the community. Similar findings were reported by Oradei and Waite (1974), whose hospitalbased stroke unit patients indicated better understanding of their impairment, its functional limitations, and how to cope with depression and loneliness following group counseling.

Singler (1982) argued that strategies for clients who have sustained CVA must capitalize on group members' current needs and remaining strengths, such as the need to talk about oneself, the fear of future strokes, and awareness of physical losses and the resulting limitations. In developing her hospital-based group, Singler set the goals of reducing anxiety and heightening emotionalism through a supportive atmosphere and the opportunity to ventilate feelings, fostering increased self-acceptance, rebuilding damaged selfesteem, and reducing social isolation. Accordingly, group discussions centered on providing members with accurate information about strokes, the therapeutic procedures involved, and the hospital setting; sharing experiences and feelings; and identifying and confronting members' most bothersome fears and problems (e.g., fear of subsequent strokes; feelings of depression, isolation, and anger; anxiety over reactions by community members). In early sessions, the group leader was directive, guiding members and 
explaining life-threatening issues. In later sessions, the group leader made indirect interpretations by questioning, thus allowing members to gain insight into their problems.

An innovative approach to group counseling with stroke and other neurologically impaired clients was reported by Evans, Halar, and Smith (1985). Their short-term cognitive therapy was aimed at assisting recently discharged patients to cope with personal issues (e.g., depression, loneliness) and to interact productively with family and friends. Evans et al. used a conference-call system to permit these nonambulatory participants to engage in discussion from their homes. The group conference took place weekly and lasted an hour. The group leader directed the flow and exchange of the group members' concerns.

Briefly, the cognitive therapy format used by Evans et al. (1985) focused on task-oriented objectives that were geared to improving mood or modifying behavior and were based on cognitive processes that affect one's attitudes and belief system. Particularly targeted were negative and rigid cognitions leading to depression and loneliness. Leaders provided participants with feedback on circular, faulty, and destructive thought processes. Individually tailored objectives included providing accurate information on the impairment and its implications, decreasing levels of anxiety, increasing energy levels, precipitating a higher level of personal independence, and generating improved relationships with family.

Leaders of CVA groups should consider the following factors when structuring and planning activities:

\section{Participants' speech and perceptual abilities.} Because a large number of CVA individuals have speech impairments, in addition to various other perceptual, physical, and cognitive losses, the group leader has to examine the impact of these factors on the group's structure and communication modalities (Singler, 1982).

2. Individual and group goals. Based on the cognitive and verbal impairments of the group members and any observations of signs of frustration and anger among participants, group leaders should strive to develop specific and concrete goals to guide future group activities. Explicit, realistic, and attainable goals will most likely result in better attendance, motivation, and progress toward achieving goals.

3. Handling denial. Denial of their limitations by people with CVA is a rather prevalent and disturbing phenomenon. Two strategies commonly used to diffuse the long-term impact of denial are awareness raising and gentle confrontation. Youngjohn and Altman (1989) reported their results with a self-awareness group that had the aim of reducing denial of deficits in stroke and head injury patients attending a rehabilitation day hospital. Patients received explanations of the cognitive and personality changes that often accompany stroke. They also were assisted in identifying their cognitive strengths and limitations by being introduced to a wide range of cognitive tasks. Similarly, confrontational strategies were applied discreetly and cautiously (e.g., pointing out discrepancies between a client's present functional abilities and unrealistic future goals) to help penetrate the protective shield of denial.

\section{Approaches in Other Physical Disabilities Groups}

Groups have been established to address the many needs and concerns of people with a variety of other physical disabilities. For example, groups for cancer patients were reported by Cunningham and Tocco (1989), Fawzy et al. (1990), Forester, Kornfeld, Fleiss, and Thompson (1993), and Telch and Telch (1986). More recent efforts in applying group counseling principles and techniques with people with cancer include those of Nezu, Nezu, Friedman, Faddis, and Houts (1998), who developed a problem-solving therapy (PST) approach that focuses on helping group members resolve long-term interpersonal problems in the safe environment of a small therapeutic community; Simonton and Sherman (2000), who described an integrative model of group therapy that seeks to accommodate the shifting needs and concerns that unfold during the course of the disease; and Leszcz and Goodwin (1998), who described a supportive-expressive group psychotherapy model that specifically addresses the needs of women with metastatic breast cancer, focusing on facilitation of social support, improved coping, and enhanced communication among patients, their health care providers, and their family members.

In addition, groups have been developed to address the specific needs of cardiac patients (e.g., Allan \& Scheidt, 1998; Horlick, Cameron, Firor, Bhalerao, \& Baltzan, 1984; Konstam, 1995; Stern, Plionis, \& Kaslow, 1984; Subramanian \& Ell, 1989), HIV-infected or AIDS patients (e.g., Beckett \& Rutan, 1990; Kelly, 1998; Norsworthy \& Horne, 1994; Tunnell, 1991), chronic kidney and liver disease patients (e.g., Buchanan, 1975; Hollon, 1972; Stewart, Kelly, Robinson, \& Callender, 1995), patients with irritable bowel syndrome (Toner et al., 1998), organ transplant recipients (Abbey \& Farrow, 1998), people with multiple sclerosis (e.g., Crawford \& McIvor, 1985; Welch \& Steven, 1979), and people who have undergone amputations (e.g., Delehanty \& Trachsel, 1995; Fischer \& Samelson, 1971; Howard, 1983; Rogers, MacBride, Whylie, \& Freeman, 1977-1978). 


\section{Approaches in Rehabilitation Settings}

Three types of rehabilitation-specific group strategies are discussed here: structured experiential training, self-help and peer-helper groups, and vocationally related groups.

\section{Structured Experiential Training}

As defined by Lasky et al. (1984), "Structured Experiential Training (SET) is an eclectic group rehabilitation model which is especially designed to meet the needs of persons with physical disabilities and emphasizes group members' goal involvement, mutual concern, and accountability" (p. 317). The SET model synthesizes elements of educational, social support, psychotherapeutic, and coping skills strategies into a systematic framework to benefit people undergoing rehabilitation. People with disabilities share common concerns in the group sessions, where they are afforded the opportunity to capitalize on others' strengths, benefit from role models, and gain more awareness and sensitivity to issues such as stress and stigma. This communication among group members increases mutual trust and understanding.

Methodologically, SET uses structured experiential learning, the power of the group process, and explicit goal orientation directed at acquiring skills and resolving related therapeutic issues. Various structured experiences related to group and personal functioning are incorporated. These structured experiences are used as interventions to facilitate the group's process and involve a set of specific instructions to participants. The five steps in this process are (a) experiencing an activity, (b) publishing or sharing reactions or observations about the activity, (c) processing the activity with other participants, (d) generalizing from the experience, and (e) applying this new learning behaviorally.

Group Organization Prospective members are oriented to the expectations of the SET format, and group members are selected based on their potential to gain from the experience as well as their commitment to the SET process and the goals delineated in the initial group contract. A typical group consists of a group leader or co-leaders and 6 to $10 \mathrm{mem}$ bers. The group meets once a week for 3 hours.

Group composition is limited to people who show the motivation and capability to work toward personally relevant goals. Participants are required to keep a daily record to help raise self-awareness, develop and clarify individual and group goals, and assist the group in becoming more cohesive.

Phases The SET process involves three sequential phases (Lasky et al., 1984): personal, group, and life and living.

1. Personal phase. This personally oriented stage involves (a) acquainting group members with one another and with the purpose of the group; (b) selecting individual goals and determining the strategies and steps necessary to attain them; and (c) actively pursuing and implementing these goals.

2. Group phase. The group-oriented stage entails (a) convergence, or joint group work to identify a common goal for all members; (b) implicit mutuality, or assessing interpersonal relationships and the implications of these relationships; (c) interpersonal feedback; and (d) explicit mutuality, or the demonstration of genuine concern for other group members.

3. Life and living phase. The third phase, life and living, calls for (a) utilization, or the application of new knowledge and experience to daily living; (b) congruence, or the demonstration of consistent integration of thought, feeling, and action; (c) commencement, or the sharing of mutual experiences and future perspectives; and (d) reunion, or the opportunity for group members to come together after the group has ended to share successes and failures.

Specific structured experiential tasks are employed as interventions to facilitate development of the group, completion of each phase, and movement of the members through the SET process.

SET Focus The consistent themes throughout the SET process are the emphases on goal involvement, mutual concern, and accountability (any of which may be the focus of any group meeting). Selected goals are expected to be relevant, understandable, performable, measurable, attainable, and time limited. The concept of mutual concern requires members to extend themselves to others in the group, to learn to rely on the group, and to provide other group members with the support and caring that are necessary for growth. Accountability takes the form of personal and interpersonal responsibility. Group members are responsible for their behavior and are not allowed to attribute personal problems to external forces.

\section{Self-Help and Peer-Helper Groups}

Self-help and peer-helper groups for individuals with disabilities have been flourishing for more than three decades. Most have been spearheaded by citizen and consumer advocacy groups sparked by the civil rights movement of the $1960 \mathrm{~s}$ (Rhoades, 1986). The early groups were initiated by and for parents whose children had disabling conditions. Now the self-help movement is geared more directly toward people with disabilities. Like the peer-support programs developed for those affected by alcoholism, peer-helper groups have been established for people who have experienced heart disease, stroke, spinal cord injuries, amputations, neurological 
disorders, cancer, mental retardation, and many other disabling conditions.

These self-governing groups, composed of individuals who share a common condition or experience, offer direct, active, and effective interventions to the participants while allowing them to avoid the stigma frequently associated with seeking outside professional help (Lieberman \& Borman, 1979). Because the person with difficulty promotes his or her own advocacy, self-help and peer-helper groups afford their members a chance at a rightful and equal place in society at large (Rhoades, Browning, \& Thorin, 1986).

The operational principles underlying the self-help philosophy, cogently stated by Jaques and Patterson (1974), are:

- Participants have a commonly shared personal problem or condition.

- All participants maintain an equal status (i.e., due to peer relationships).

- Peers come together with the expectation of helping themselves and one another.

- All participants seek behavioral change.

- Peers identify with the particular program developed by the group and actively support this program.

- The group process consists of participants' actively relating, owning, and sharing experiences, hopes, and problems; receiving feedback from, and giving feedback to, one another; and providing encouragement and criticism.

- Participants are held responsible for themselves and their behaviors.

- Group leadership develops and changes from within the group and follows the program's principles and goals.

Self-help groups serve many important functions in the lives of people with disabilities, including the following:

1. Provision of accurate knowledge. Members can gain information (e.g., medical facts, innovative treatment and rehabilitation modalities) about their disability.

2. Development of coping strategies. Members can learn adaptive coping strategies from others who have learned to successfully live with the same or a similar disability. They also benefit from the social modeling of others who demonstrate problem-solving behaviors that are useful for life in the community and from the feedback they provide newer members (Wright, 1983).

3. Increase in motivation level. Members can become more motivated to achieve their rehabilitation goals by openly sharing and communicating with others who have similar conditions and life experiences.
Self-help groups provide a psychosocial support network, creating opportunities for receiving and giving emotional support and solving mutual problems (Gottlieb, 1982).

4. Identification with a social reference group. By offering identification with a social reference group, self-help groups give members a sense of rootedness and belonging, thereby decreasing feelings of isolation, rejection, and alienation (Plummer, 1982).

5. Opportunities for self-evaluation. Groups can provide members with concrete evidence of selfprogress. This evaluative function is closely linked to the type of feedback received from the group leader and other members as the various phases of members' problems and coping efforts unfold (Jaques \& Patterson, 1974).

6. Active participation in services. Groups enable members to surrender the role of passive recipient of services to the role of active participant. This action orientation is germane to the rehabilitation philosophy that those in rehabilitation are responsible consumers who choose among various alternatives, ultimately manage their individual rehabilitation plans, and are accountable for their results (Plummer, 1982).

\section{The Job Club}

The job club method exemplifies a behavioral group approach to vocational counseling and job placement. It centers on individual needs and uses reinforcement and peer support to help members "obtain a job of the highest feasible quality within the shortest feasible time period for all participating job seekers" (Azrin \& Besalel, 1980, p. 1).

Each procedure employed in the job club approach is standardized into a consistent, intensive process for all job seekers (Azrin \& Philip, 1979). Group members work together under the instruction and encouragement of a leader who provides support, information, and supplies. Azrin and Besalel (1980) specified more than 30 procedures and activities used with this approach, including practice with standard scripts and forms, group support from other job seekers, a buddy system, use of the telephone, emphasis on personal skills, interview training, transportation, daily progress charts, and continued assistance.

In the job club model, job search and related activities are scheduled within the club session as much as possible so immediate assistance can be given for such activities as resumé and letter writing, calling friends and former employers for leads, calling potential employers for interviews, reviewing job listings in newspapers and other available sources, and planning daily and weekly job seeking activities. The group leader's role requires a commitment to 
help every member obtain an appropriate job through selective placement; the leader provides job leads, encouragement, and a positive perspective focused on the members' assets, not limitations.

Before the job club is initiated, an intake group may be conducted to orient members to the job club program, basic hygiene, health and living skills, work behavior and ethics, and the world of work. Typically meeting for 8-10 weeks, once a week for $1 \frac{1}{2}$ to 2 hours, the intake group prepares the members to apply these new knowledge areas and skills in the job club. The job club itself may meet from 1 to 5 days per week and is a continuous resource to be tapped by members, who may reenter at any time, usually for only minimal assistance.

The job club approach is efficient because it can address every participant at the same time and reinforce members' behaviors and achievements in the presence of all other members. Not only does the approach offer support, but it also encourages others to follow examples of peer success. In addition, it shows group members how to engage in mutual support endeavors, confront similar problems, share resources, and offer peer support. Because many of the demands of work are largely social in nature (e.g., accepting criticism, attending to directions) and because of the heavy emphasis on the team approach in today's workplace, employers are increasingly concerned with the job seeker's ability to work as a team member (Johnson, Greenwood, \& Schriner, 1988). Research on applying the group method to work adjustment and job placement supports the hypothesis that participants in job-seeking groups are seen as more competent overall and better prepared for the jobs (Garvin, 1984; Roessler, 1986).

McWhirter and McWhirter (1996) described a group model similar to that of the job club, which they termed the transition-to-work group. In their group, college students with learning disabilities prepared for dealing with the personal, professional, vocational, and legal aspects encountered upon entering the work arena. The five sessions of the group focused sequentially on the following themes: setting group format and establishing group cohesion, building selfconfidence and communicating about the disability, examining and keeping records of job and market trends, discussing legal issues regarding employment and disability, and learning practical strategies to compensate for the disability in the work setting. Preliminary feedback data from group participants seem to confirm the beneficial results of the transitionto-work group experience.

\section{AGE-SPECIFIC VARIATIONS}

Important considerations in groups for people with physical disabilities are the members' age and the age of onset of the disability. The latter was discussed for different types of disabling conditions under "Strategies for Group Sessions." Here, the focus is on variables related to present age.

\section{Considerations for Groups With Younger People}

Goals for children and adolescent groups differ from those for adult groups (Gazda, Ginter, \& Horne, 2001; Kennedy, 1989; Marshak, 1982) because they need to consider factors such as levels of psychosocial and cognitive functioning, self-identity, self-insight, social maturity, and attained level of independence. In general, goals in groups for children and adolescents should be narrower and should focus on solving present problems and issues (Marshak, 1982). In groups of youth with disabilities, the leader should also consider the following strategies and issues:

1. Initiating and maintaining a more active style than that practiced with adults, to counteract the passive or resistant attitude commonly seen in adolescent clients (Bruce, 1975).

2. Being aware of the negative impact of long periods of silence during group sessions (Marshak, 1982). Adolescents seem to react more adversely to silence and to breakdowns in communication (e.g., by becoming anxious). Their adverse reactions impede the group counseling process, especially with participants who have visual and hearing impairments.

3. Self-disclosing personal feelings. Showing members that owning a wide range of feelings, rather than resorting to denying them or being overwhelmed by them, is normal can be a valuable clinical tool (Marshak, 1982).

4. Making cautious and limited use of interpretations. The aim in these groups of youth should be behavioral and functional improvement and setting and implementing specific, time-bound goals. Berkovitz (1972) and Marshak (1982) maintained that attempts at in-depth interpretation, and especially interpreting transference in a group setting, can have a negative impact on younger members. Members' level of cognitive and social maturity should play a prominent part in deciding the use, type, and timing of interpretation.

5. Discretely using role-playing and psychodrama exercises. Although these strategies are often recommended in the literature (Marshak, 1982; Sussman, 1974), they are not without their pitfalls. Role-playing, especially with members who have sensory impairments, is rather common. However, before using role-playing, psychodrama, or similar techniques (e.g., music therapy, movement therapy), the group leader should weigh the members' ability to 
ambulate (in the case of participants with SCI, muscular dystrophy, and so forth); the members' body images (especially in the case of young adolescents, whose perception of their own bodies is precarious); and the level of group cohesiveness (e.g., in open groups, new members with body deformities may find role-playing extremely threatening, particularly in early sessions).

6. Paying special attention to the youngsters' typical concerns, which, in addition to the visible physical impairment, include the age-related concerns of physical appearance, peer acceptance, self-identity, sexuality, emancipation from family, and the like (Kennedy, 1989; Weinman, 1987).

7. When appropriate, requesting that parents or other family members allow the youngsters to attend the group sessions alone, without their company. If group sessions are conducted in inpatient settings (e.g., hospital wards), parents may be requested to remain outside the room in which the sessions are held (Flynn, 1992).

The presence of a physical disability compromises adolescents' accomplishment of various developmental tasks (Manaster, 1977). According to Marshak (1982), the tasks most affected are (a) acquiring more mature relationships with peers of both genders, (b) acquiring feminine or masculine social roles, (c) accepting one's physique and use of body, and (d) becoming emotionally independent from parental figures. Group leaders should give equal consideration to the stresses associated with these and the previously discussed age-related developmental tasks, the presence of physical impairment, and attitudes of parents and peers (e.g., overprotection, rejection) when selecting group strategies for adolescents with disabilities.

\section{Considerations for Groups With Older Adults}

Goals for older adults with physical disabilities also must accommodate participants' age-related sensory, physical, and cognitive (e.g., memory) deteriorations.

When counseling older adults, the group leader is often required to consider an age-specific set of therapeutic goals (Kalson, 1982). The factors that exert the greatest impact on the lives of older individuals include loss of significant others; disruption of social support systems; loss of independence and control over one's life, resulting from physical deterioration; economic and financial concerns; cognitive changes (e.g., impairment of recent memory); and fear of institutionalization (Gugel \& Eisdorfer, 1985; Kalson, 1982).

The group leader who works with older adults may also have to consider time constraints. Long-term goals should be carefully selected, with particular attention paid to setting time limits on goals and their implementation (Kalson, 1982). In group counseling settings, the leader should:

1. Be brief and direct in approach (Kalson, 1982), which will expedite group cohesiveness and the development of individual and group goals.

2. Attend to members' organic conditions. Cognitive deficits related to organicity may exacerbate physical and sensory impairments (e.g., those resulting from stroke or head injuries). Kalson (1982) recommended that to assess a group member's level of organic brain involvement, the leader should arrange for tests of the member's general intelligence, shortterm memory, orientation as to place and person, and judgment. If organicity is present, the counseling style should be modified to (a) allow the member more time to respond to the leader and other participants, (b) be much more concrete in content, and (c) clearly and slowly present the member with simply worded questions.

3. Be aware of the complex set of transference responses exhibited in this age group. According to Linden (1955), two of the more common types of transference displayed by older adults are recession and sociological transference. In recession transference, social unlearning or a return to repressed material occurs. This results in a series of reverse steps of psychosexual development, leading to an inversion of the parent-child relationship. The younger leader, then, is perceived in the role of a parent. In sociological transference, the older member manifests signs of self-rejection because of identification with cultural beliefs upholding the value of youth and physical prowess. Group leaders who seek to facilitate the therapeutic effect of transference and its interpretation may heed Linden's (1954) advice to install dualgender group leadership in an effort to replicate the original family structure.

4. Take a flexible approach in structuring and pacing sessions. Because of the numerous life crises (e.g., impaired mobility, retirement, death of mate, impending death) that beset older people with and without disabilities, group leaders should be prepared to deviate, when necessary, from planned group topics and address the more immediate needs of individual members.

Many authors have advocated a greater use of therapeutic group programs for people in nursing homes. Gugel and Eisdorfer (1985) posited that the functional level of older people may be improved by recreation therapy, occupational 
therapy, reality orientation, remotivation programs, behavior therapy, and environmental (milieu) approaches.

\section{SUMMARY}

Group counseling has been used with a wide range of people who have physical disorders including psychosomatic conditions, sensory (visual and auditory) disabilities, neuromuscular and orthopedic impairments, and life-threatening diseases. The needs and concerns of these people can be generally delineated as physical, psychological, social, vocational, financial, environmental, attitudinal, and recreational. The four modalities used most often are educational, social support, psychotherapeutic, and coping and skill training groups. Goal setting addresses affective, cognitive, and behavioral areas.

People with visual impairments have concerns generally related to their reduced mobility, dependence on others, limited social skills, anxiety and avoidance of people, altered body image, and coping with the reality and limitations of the disability. Groups for people with hearing impairments focus on communication, negotiating the environment, compensating for experiential deprivation and isolation, adaptive behavior patterns, handling frustrations, and overdependency.

Neuromuscular injury groups are often geared toward individuals with spinal cord injury and those who have had cerebrovascular accidents (strokes). The former typically have difficulties with mobility, self-care, sexual performance, and affective aspects. The latter have perceptual-spatial deficits, cognitive impairments, affective problems, behavioral involvement, and communication difficulties. Finally, groups for people coping with life-threatening diseases focus on adaptive coping strategies necessitated by the progressive course of the disease.

In groups addressing all of these needs, the provision of information is a fundamental strategy. Providing information is also important in approaches in rehabilitation settings, which include the structured experiential training model, self-help and peer-helper groups, and the job club model.

Groups with younger people are necessarily different from groups with older people because of developmental factors unique to each age group. Other important variables are age of onset of the disability and whether the disability was present at birth or occurred later.

\section{REFERENCES}

Abbey, S., \& Farrow, S. (1998). Group therapy and organ transplantation. International Journal of Group Psychotherapy, 48, 163-185.

Allan, R., \& Scheidt, S. (1998). Group psychotherapy for patients with coronary heart disease. International Journal of Group Psychotherapy, $48,187-214$.
Anderson, T. P. (1981). Stroke and cerebral trauma: Medical aspects. In W. C. Stolov \& M. R. Clowers (Eds.), Handbook of severe disability (pp. 119-126). Washington, DC: U.S. Department of Education.

Andersson, G., Melin, L., Scott, B., \& Lindberg, P. (1995). An evaluation of a behavioural treatment approach to hearing impairment. Behaviour Research and Therapy, 33, 283-292.

Avery, C. (1968). Para-analytic group therapy with adolescent multi-handicapped blind. New Outlook for the Blind, 68, 65-72.

Azrin, N. H., \& Besalel, V. (1980). Job Club counselor's manual: A behavioral approach to vocational counseling. Baltimore, MD: University Park Press.

Azrin, N. H., \& Philip, R. A. (1979). The Job Club method for the jobhandicapped: A comparative outcome study. Rehabilitation Counseling Bulletin, 23, 144-155.

Banik, S. N., \& Mendelson, M. A. (1978). Group psychotherapy with a paraplegic group with an emphasis on specific problems of sexuality. International Journal of Group Psychotherapy, 28, 123-128.

Beckett, A., \& Rutan, J. S. (1990). Treating persons with ARC and AIDS in group psychotherapy. International Journal of Group Psychotherapy, 40, 19-29.

Berkovitz, I. H. (1972). Adolescents grow in groups. New York: Brunner/ Mazel.

Bowers, J. E., Clark-Mahoney, J. P., Forshee, T., Reiner, K. A., Schilling, J. E., \& Snyder, B. S. (1987). Analysis of a support group for young spinal cord-injured males. Rehabilitation Nursing, 12, 313-315, 322.

Bruce, T. J. (1975). Adolescent groups and the adolescent process. British Journal of Medical Psychology, 48, 333-338.

Buchanan, D. C. (1975). Group therapy for kidney transplant patients. International Journal of Psychiatry in Medicine, 6, 523-531.

Card, K. J., \& Schmider, L. (1995). Group work with members who have hearing impairments. Journal for Specialists in Group Work, 20, 83-90.

Cholden, L. (1953). Group therapy with the blind. Group Psychotherapy, 6, 21-29.

Chubon, R. A. (1982). Group practices in the rehabilitation of physically disabled persons. In M. Seligman (Ed.), Group psychotherapy and counseling with special populations (pp. 59-76). Baltimore, MD: University Park Press.

Craig, A., Hancock, K., Chang, E., \& Dickson, H. (1998). The effectiveness of group psychological intervention in enhancing perceptions of control following spinal cord injury. Australian and New Zealand Journal of Psychiatry, 32, 112-118.

Crawford, J. D., \& McIvor, G. P. (1985). Group psychotherapy: Benefits in multiple sclerosis. Archives of Physical Medicine \& Rehabilitation, 66, 810-813.

Crewe, N. M., \& Krause, J. S. (1987). Spinal cord injury: Psychological aspects. In B. Caplan (Ed.), Rehabilitation psychology desk reference (pp. 3-35). Rockville, MD: Aspen.

Cunningham, A. J., \& Tocco, E. K. (1989). A randomized trial of group psychoeducational therapy for cancer patients. Patient Education and Counseling, 14, 101-114.

D’Afflitti, J. G., \& Weitz, G. W. (1974). Rehabilitating the stroke patient through patient-family groups. International Journal of Group Psychotherapy, 24, 323-332.

Delehanty, R. D., \& Trachsel, L. (1995). Effects of short-term group treatment on rehabilitation outcome of adults with amputations. International Journal of Rehabilitation and Health, 1(2), 61-73.

Democker, J. D., \& Zimpfer, D. G. (1981). Group approaches to psychosocial intervention in medical care: A synthesis. International Journal of Group Psychotherapy, 31, 247-260.

Donovan, W. H. (1981). Spinal cord injury. In W. C. Stolov \& M. R. Clowers (Eds.), Handbook of severe disability (pp. 65-82). Washington, DC: U.S. Department of Education. 
Durkin, H. E. (1972). Group therapy movement. Psychiatric Annals, 2, 14-23

Evans, R. L., Halar, E. M., \& Smith, K. M. (1985). Cognitive therapy to achieve personal goals: Results of telephone group counseling with disabled adults. Archives of Physical Medicine \& Rehabilitation, 60, 693-696.

Fawzy, F. I., Cousins, N., Fawzy, N. W., Kemeny, M. E., Elashoff, R., \& Morton, D. (1990). A structured psychiatric intervention for cancer patients. Archives of General Psychiatry, 47, 720-725.

Fischer, W. G., \& Samelson, C. F. (1971). Group psychotherapy for selected patients with lower extremity amputation. Archives of Physical Medicine \& Rehabilitation, 52, 79.

Flynn, D. (1992). Adolescent group work in a hospital in-patient setting with spina bifida patients and others. Journal of Child Psychotherapy, $18,87-102$.

Forester, B., Kornfeld, D. S., Fleiss, J. L., \& Thompson, S. (1993). Group psychotherapy during radiotherapy: Effects on emotional and physical distress. American Journal of Psychiatry, 150, 1700-1706.

Fow, N. R., \& Rockey, L. S. (1995). A preliminary conceptualization of the influence of personality and psychological development on group therapy with spinal cord patients. Journal of Applied Rehabilitation Counseling, 26(1), 30-32.

Garvin, R. E. (1984). Vocational exploration and job search activities in a group setting. Journal of Applied Rehabilitation Counseling, 15(1), $15-17$.

Gazda, G. M., Ginter, E. J., \& Horne, A. E. (2001). Group counseling and group psychotherapy: Theory and application. Boston: Allyn \& Bacon.

Goldman, H. (1970). The use of encounter microlabs with a group of visually handicapped rehabilitation clients. New Outlook for the Blind, 64 , 219-226.

Gottlieb, B. H. (1982). Mutual-help groups: Members' views of their benefits and roles for professionals. In L. D. Borman, L. E. Borck, R. Hess, \& F. L. Pasquale (Eds.), Prevention in human services: Vol. 1. Helping people to help themselves-Self-help and prevention (pp. 55-68). New York: Haworth Press.

Gugel, R. N., \& Eisdorfer, S. (1985). The role of therapeutic group programs in a nursing home. Rehabilitation Psychology, 30, 83-92.

Gust, T. (1970). Group counseling with rehabilitation clients. Rehabilitation Record, 11, 18-25.

Henkle, C. (1975). Social group work as a treatment modality for hospitalized people with rheumatoid arthritis. Rehabilitation Literature, 36 , 334-341.

Herman, S. (1966). Some observations on group therapy with the blind. International Journal of Group Psychotherapy, 16, 367-372.

Hollon, T. H. (1972). Modified group therapy in the treatment of patients on chronic hemodialysis. American Journal of Psychotherapy, 36, 501-510.

Horlick, L., Cameron, R., Firor, W., Bhalerao, U., \& Baltzan, R. (1984). The effects of education and group discussion in the post myocardial infarction patient. Journal of Psychosomatic Research, 28, 485-492.

Howard, D. L. (1983). Group therapy for amputees in a ward setting. Military Medicine, 148, 678-680.

Inana, M. (1978). You and your body: A self-help health class for blind women. Journal of Visual Impairment \& Blindness, 72, 399-403.

Jacobs, E. E., Harvill, R. L., \& Masson, R. L. (1988). Group counseling: Strategies and skills. Pacific Grove, CA: Brooks/Cole.

Jaques, M., \& Patterson, K. W. (1974). The self-help group model: A review. Rehabilitation Counseling Bulletin, 18, 48-58.

Johnson, A. J., Greenwood, R., \& Schriner, K. F. (1988). Work performances and work personality: Employer concerns about workers with disabilities. Rehabilitation Counseling Bulletin, 32, 50-57.
Kalson, L. (1982). Group therapy with the aged. In M. Seligman (Ed.), Group psychotherapy and counseling with special populations (pp. 77-97). Baltimore, MD: University Park Press.

Keegan, D. L. (1974). Adaptation to visual handicap: Short-term group approach. Psychosomatics, 15, 76-78

Kelly, J. A. (1998). Group psychotherapy for persons with HIV and AIDSrelated illnesses. International Journal of Group Psychotherapy, 48(2), $143-162$.

Kennedy, J. F. (1989). The heterogeneous group for chronically physically ill and physically healthy but emotionally disturbed children and adolescents. International Journal of Group Psychotherapy, 39, 105-125.

Konstam, V. (1995). Anger: A neglected group treatment issue with cardiac transplantation recipients and their families. Journal for Specialists in Group Work, 20, 189-194.

Kriegsman, K. H., \& Celotta, B. (1981). Creative coping: A program of group counseling for women with physical disabilities. Journal of Rehabilitation, 47, 36-39.

Lasky, R. G., \& Dell Orto, A. E. (Eds.). (1979). Group counseling and physical disability: A rehabilitation and health care perspective. North Scituate, MA: Duxbury Press.

Lasky, R. G., Dell Orto, A. E., \& Marinelli, R. P. (1984). Structured experiential training: A group rehabilitation model. In R. P. Marinelli \& A. E. Dell Orto (Eds.), The psychological and social impact of physical disability (2nd ed., pp. 304-330). New York: Springer.

Leszcz, M., \& Goodwin, P. J. (1998). The rationale and foundations of group psychotherapy for women with metastatic breast cancer. International Journal of Group Psychotherapy, 48(2), 245-273.

Lieberman, M. A., \& Borman, L. D. (Eds.). (1979). Self-help groups for coping with crisis. San Francisco: Jossey-Bass.

Lindemann, J. E. (1981). Psychological and behavioral aspects of physical disability. New York: Plenum Press.

Linden, M. (1954). The significance of dual leadership in gerontologic group psychotherapy: Studies in gerontologic human relations III. International Journal of Group Psychotherapy, 4, 262-273.

Linden, M. (1955). Transference in gerontologic group therapy: Studies in gerontologic human relations IV. International Journal of Group Psychotherapy, 5, 61-79.

Lyons, R. F., Sullivan, M. J., \& Ritvo, P. G. (1995). Relationships in chronic illness and disability. Thousand Oaks, CA: Sage.

Manaster, G. J. (1977). Adolescent development and the life tasks. Boston: Allyn \& Bacon.

Mann, W., Godfrey, M. E., \& Dowd, E. T. (1973). The use of group counseling procedures in the rehabilitation of spinal cord injured patients. American Journal of Occupational Therapy, 27, 73-77.

Marshak, L. (1982). Group therapy with adolescents. In M. Seligman (Ed.), Group psychotherapy and counseling with special populations (pp. 185-213). Baltimore, MD: University Park Press.

McWhirter, P. T., \& McWhirter, J. J. (1996). Transition-to-work group: University students with learning disabilities. Journal for Specialists in Group Work, 21, 144-148.

Melnyk, R., Montgomery, R., \& Over, R. (1979). Attitude changes following sexual counseling program for spinal cord injured persons. Archives of Physical Medicine \& Rehabilitation, 60, 601-605.

Miller, D. K., Wolfe, M., \& Spiegel, M. H. (1975). Therapeutic groups for patients with spinal cord injuries. Archives of Physical Medicine \& Rehabilitation, 56, 130-135.

Nezu, A. M., Nezu, C. M., Friedman, S. H., Faddis, S., \& Houts, P. S. (1998). Helping cancer patients cope. Washington, DC: American Psychological Association.

Norsworthy, K. L., \& Horne, A. M. (1994). Issues in group work with HIVinfected gay and bisexual men. Journal for Specialists in Group Work, 19. 112-119. 
Olkin, R. (1999). What psychotherapists should know about disability. New York: Guilford.

Oradei, D. M., \& Waite, N. S. (1974). Group psychotherapy with stroke patients during the immediate recovery phase. American Journal of Orthopsychiatry, 44, 386-395.

Ostby, S., \& Thomas, K. R. (1984). Deafness and hearing impairment: A review and proposal. Journal of Applied Rehabilitation Counseling, 15(2), 7-11.

Patterson, J. B., McKenzie, B., \& Jenkins, J. (1995). Creating accessible groups for individuals with disabilities. Journal for Specialists in Group Work, 20, 76-82.

Plummer, S. J. (1982). Independent living centers: A self-help group model for the severely disabled. In M. Seligman (Ed.), Group psychotherapy and counseling with special populations (pp. 117-142). Baltimore, MD: University Park Press.

Portner, D. (1981). Clinical aspects of social group work with the deaf. Social Work With Groups, 4, 123-133.

Power, P. W., \& Rogers, S. (1979). Group counseling for multiple sclerosis patients: A preferred model of treatment for unique adoptive problems. In R. G. Lasky \& A. E. Dell Orto (Eds.), Group counseling and physical disability: A rehabilitation and health care perspective (pp. 115-127). North Scituate, MA: Duxbury Press.

Rhoades, C. (1986). Different organizational models for self-help advocacy groups that serve people with developmental disabilities. Journal of Rehabilitation, 52, 43-47.

Rhoades, C. M., Browning, P. L., \& Thorin, E. J. (1986). Self-help advocacy movement: A promising peer-support system for people with mental disabilities. Rehabilitation Literature, 47, 2-7.

Riekehof, L. L. (1987). The joy of signing (2nd ed.). Springfield, MO: Gospel.

Robinson, L. D. (1965). Group therapy using manual communication. Mental hospitals. Washington, DC: American Psychiatric Association.

Roessler, R. T. (1978). An evaluation of personal achievement skills training with the visually handicapped. Rehabilitation Counseling Bulletin, 21, 300-305.

Roessler, R. T. (1986). Training for vocational coping: A method for enhancing work establishment skills. Rehabilitation Counseling Bulletin, 29, 258-265.

Roessler, R. T., Milligan, T., \& Ohlson, A. (1976). Personal adjustment training for the spinal cord injured. Rehabilitation Counseling Bulletin, 19, 544-550.

Rogers, J., MacBride, A., Whylie, B., \& Freeman, S. J. (1977-1978). The use of groups in the rehabilitation of amputees. International Journal of Psychiatry in Medicine, 8, 243-255.

Rose, S. D. (1989). Coping skill training in groups. International Journal of Group Psychotherapy, 39, 59-78.

Routh, T. A. (1957). A study of the use of group psychotherapy in rehabilitation centers for the blind. Group Psychotherapy, 10, 38-50.

Salhoot, J. T. (1977). Group strategies with the severely physically handicapped. In M. Seligman (Ed.), Group counseling and group psychotherapy with rehabilitation clients (pp. 149-172). Springfield, IL: Charles C Thomas.

Sarti, D. M. (1993). Reaching the deaf child: A model for diversified intervention. Smith College Studies in Social Work, 63, 187-198.

Scheidlinger, S. (1984). Group psychotherapy in the 1980s: Problems and prospects. American Journal of Psychotherapy, 38, 494-504.

Schein, J. D. (1982). Group techniques applied to deaf and hearingimpaired persons. In M. Seligman (Ed.), Group psychotherapy and counseling with special populations (pp. 143-161). Baltimore, MD: University Park Press.

Sedge, S. K. (1982). Assertiveness training with hearing-impaired persons. Rehabilitation Counseling Bulletin, 25, 146-152.
Seligman, M. (1982). Introduction. In M. Seligman (Ed.), Group psychotherapy and counseling with special populations (pp. 1-26). Baltimore, MD: University Park Press.

Silberman-Miller, M., \& Moores, D. F. (1990). Principles of group counseling and their applications for deaf clients. Journal of the American Deafness and Rehabilitation Association, 23, 82-87.

Simonton, S., \& Sherman, A. (2000). An integrated model of group treatment for cancer patients. International Journal of Group Psychotherapy, 48(2), 487-506.

Singler, J. K. (1982). The stroke group: Planning for success. In M. Seligman (Ed.), Group psychotherapy and counseling with special populations (pp. 43-57). Baltimore, MD: University Park Press.

Speer, D. C., \& O’Sullivan, M. J. (1994). Group therapy in nursing homes and hearing deficit. Clinical Gerontologist, 14, 68-70.

Stern, M. J., Plionis, E., \& Kaslow, L. (1984). Group process expectations and outcome with post-myocardial infarction patients. General Hospital Psychiatry, 6, 101-108.

Stewart, A. M., Kelly, B., Robinson, J. D., \& Callender, C. D. (1995). The Howard University Hospital transplant and dialysis support group: Twenty years and going strong. International Journal of Group Psychotherapy, 45, 471-488.

Subramanian, K., \& Ell, K. O. (1989). Coping with a first heart attack: A group treatment model for low-income Anglo, black, and Hispanic patients. Social Work With Groups, 11, 99-117.

Sussman, A. E. (1974). Group therapy with severely handicapped. Journal of Rehabilitation of the Deaf, 8, 122-126.

Telch, C. F., \& Telch, M. J. (1986). Group coping skills instruction and supportive group therapy for cancer patients: A comparison of strategies. Journal of Consulting \& Clinical Psychology, 54, 802-808.

Toner, B. A., Segal, Z. V., Emmott, S., Myran, D., Ali, A., DiGasbarro, I, \& Stuckless, N. (1998). Cognitive-behavioral group therapy for patients with irritable bowel syndrome. International Journal of Group Psychotherapy, 48, 215-243.

Tunnell, G. (1991). Complications in group psychotherapy with AIDS patients. International Journal of Group Psychotherapy, 41, 481-498.

Van Boemel, G. B., \& Rozee, P. D. (1992). Treatment for psychosomatic blindness among Cambodian refugee women. Women and Therapy, 13, 239-266.

Vander Kolk, C. J. (1983). Rehabilitation counseling with the visually impaired. Journal of Applied Rehabilitation Counseling, 14(3), 13-19.

Weiner, W. (1988). Groups for the terminally ill cardiac patient. In B. W. MacLennan, S. Saul, \& M. B. Weiner (Eds.), Group psychotherapies for the elderly. (pp. 165-175). Madison, CT: International Universities Press.

Weinman, B. (1987). Membership retention in group therapy among adolescents who are physically disabled. Journal of Rehabilitation, 53, $52-55$.

Welch, G. J., \& Steven, K. (1979). Group work intervention with a multiple sclerosis population. Social Work With Groups, 2, 221-234.

Welsh, R. L. (1982). The use of group strategies with the visually impaired. In M. Seligman (Ed.), Group psychotherapy and counseling with special populations (pp. 163-184). Baltimore, MD: University Park Press.

Wilson, E. L. (1972). Programming individual and adjunctive therapeutic services for visually impaired clients in a rehabilitation center. New Outlook for the Blind, 66, 215-220.

Wright, B. A. (1983). Physical disability: A psychosocial approach (2nd ed.). New York: Harper \& Row.

Yalom, I. D. (1985). The theory and practice of group psychotherapy (3rd ed.). New York: Basic Books.

Youngjohn, J. R., \& Altman, I. M. (1989). A performance-based group approach to the treatment of anosognosia and denial. Rehabilitation Psychology, 34, 217-222. 


\title{
Curriculum Planning and Instructional Design for Gifted Learners
}

\author{
Joyce VanTassel-Baska
}

This comprehensive text establishes an exciting curriculum design model that caters to the unique needs of the gifted learner. While giving careful consideration to the current climate of educational reform, the text is able to preserve and enhance the important enterprise of gifted education.

The author's extensive experience in the field of gifted education makes this text an invaluable resource for students and teachers alike. Impressive in scope, the text gives thorough attention to crucial issues such as effective curriculum delivery, implementation strategies, and learner-outcome assessment.

Curriculum goals, learner outcomes, teacher-learning activities, instructional strategy design and selection, and management activities are among the important topics addressed in the individual chapters. The latter part of the book contains specific helpful sample curriculum units that exemplify strategies described throughout the book.

\section{SPECIAL FEATURES}

- Provides a comprehensive framework for curriculum planning.

- Designs an effective planning model for instruction.

- Outlines specific instructional strategies and curriculum units.

- Presents guidelines for learning assessment and curriculum evaluation.

\section{CONTENTS}

1. Introduction

2. Research on Curriculum Models in Gifted Education

3. Standards of Learning and Gifted Education

4. Developing Systemwide Curriculum Documents

5. The Nature and Curriculum Needs of Gifted Learners

6. Developing a Philosophy and Goals for a Gifted Program

7. Developing Learner Outcomes

8. Designing Activities and Selecting Resources

9. Selecting Instructional Strategies

10. Employing Appropriate Curriculum Management Strategies

11. Implementing Curricula for the Gifted

12. Assessment of Learning and Evaluation of Curriculum

13. Toward Coherent Curriculum Policy in Gifted Education

Appendix: Sample Curriculum Units

\$54.00 / Paperback / 384 pages / ISBN 0-89108-292-1

Love Publishing Company

9101 E. Kenyon Ave., Suite 2200

Denver, CO 80237

303-221-7333 • 303-221-7444 (fax) 


\section{Professional update}

\section{NEW BOOKS}

\section{Teaching Early Literacy}

Development, Assessment, and Instruction

Diane M. Barone, Maria H. Mallette, and Shelley Hong Xu

This book is filled with practical assessment and instructional ideas for teachers of pre-K through grade 3. Engaging vignettes show how everyday conversations and activities offer rich opportunities both for evaluating children's current level of knowledge and for helping them progress toward more sophisticated and rewarding interactions with reading and writing. Throughout, the book highlights ways to work effectively with English language learners and their families, a theme that is the exclusive focus of two chapters. Other timely topics covered include creative uses of technology and ways to incorporate popular culture into the classroom. Over two dozen reproducible assessment tools and handouts enhance the utility of this volume as an instructional resource, professional development tool, or graduate-level text.

Hardback \& Paperback / 250 pages / 2005

Publisher: Guilford Publications

72 Spring Street, New York, NY 10012
The Teddy Bear Express Two!

Skills and Strategies for Early Academic Success

Nancy J. Bonsangue, Susanne G. Flatley, and Gerald E. Gannon

The Teddy Bear Express Two! provides intervention strategies and materials for children three to five years of age consistent with their developmental readiness level. The program consists of units, each of which contains four supporting lessons in communication, academics, motor skills, and social relationships.

The units include friends, colors, shapes, words, nature, transportation, senses, community helpers, seasons, and much more. The activities are process-oriented and allow children to explore and create from their own imaginations. The experiences help children with the development of reading, writing, and mathematical thoughts. It includes assessment procedures to measure development within targeted areas. The communication sheets for sending home to parents are in both Spanish and English.

Paperback / 81/2 x $11 / 200$ pages / 2005

Publisher: Love Publishing Company

9101 E. Kenyon Ave., Denver, CO 80237 